\title{
Inclusão Digital para quê e para quem? Observação do Portal Inclusão Digital do Governo Federal Brasileiro
}

\author{
Digital Inclusion: why and for whom? Observation of the Brazilian federal government's digital inclusion website \\ ¿Inclusión Digital para qué y para quién? Una Observación del Portal Inclusión Digital del Gobierno Federal \\ Brasileño
}

\section{Resumo}

A finalidade deste artigo é observar e analisar o Portal de Inclusão Digital do Governo Federal Brasileiro em termos das Ações, Projetos, Programas e Documentos de âmbito federal, apontando seus objetivos e público-alvo. A metodologia se deu por navegação orientada, a qual foi a principal fonte dos dados, definindo o modo de correr links e páginas virtuais. Os resultados encontrados indicam que o Portal governamental, em relação ao tema Inclusão Digital, está desatualizado quanto a informações sobre suas ações, projetos, programas e documentos, pois muitas de suas páginas estão vazias e alguns dos programas e projetos apresentados foram descontinuados.

Palavras-chave: Inclusão digital; inclusão social; governo federal; governo eletrônico; tecnologia da informação e comunicação.

Kleomara Gomes Cerquinho - kleogc@gmail.com

Professora da Universidade Federal do Amazonas, Faculdade de Estudos Sociais, Manaus, AM, Brasil.

Wellington Tavares - emaildotom12@yahoo.com.br

Universidade Federal de Ouro Preto, Departamento de Gestão Pública, Ouro Preto, MG, Brasil

Ana Paula Paes de Paula - appp.ufmg@gmail.com

Universidade Federal de Minas Gerais, Faculdade de Ciências Econômicas, Departamento de Ciências Administrativas, Belo Horizonte, MG, Brasil.

Irineu Amaro Vitorino - irineuvitorino@gmail.com

Mestrando da Fundação Mineira de Educação e Cultura (FUMEC), Belo Horizonte, MG, Brasil.

Artigo submetido no dia 05-09-2014 e aprovado em 03-09-2015.

DOI: http://dx.doi.org/10.12660/cgpc.v20n67.32927 


\section{Abstract}

The purpose of this article is to observe and analyze the "Portal de Inclusão Digital" [Digital Inclusion website] of the Brazilian federal government in terms of federal actions, projects, programs and documents, pointing out its goals and targets. By setting the running mode links and virtual pages a methodology is given for quided navigation, which was the main data source. The results indicate that as far as concerns digital inclusion, the government's website is out of date in terms of the information about its actions, projects, programs and documents, because many of its pages are empty and some of the programs and projects presented have been discontinued.

Keywords: digital inclusion; social inclusion; federal government; e-government; information and communication technology.

\section{Resumen}

El propósito de este artículo es observar y analizar la Inclusión Portal digital del Gobierno Federal de Brasil'en términos de las acciones, proyectos, programas y documentos federales, señalando sus objetivos y público objetivo. La metodolog ía se da para la navegación guiada, que era la principal fuente de datos estableciendo el modo de ejecutar los enlaces virtuales y páginas. Los resultados indican que el portal del gobierno, en el tema de la inclusión digital, es información obsoleta en sus acciones, proyectos, programas y documentos, ya que muchas de sus páginas están vacías y algunos de los programas y proyectos presentados se interrumpieron.

Palabras clave: inclusión digital; inclusión social; gobierno federal; gobierno electrónico; información y tecnología de comunicacion.

\section{INTRODUÇÃO}

A inclusão digital deve ser pensada como uma questão de direito à ação política e ser objeto de ações governamentais, nas quais a inserção de novos instrumentos nesse campo amplia os quatro capitais básicos para o indivíduo: social, cultural, intelectual e técnico.

Contudo, o termo inclusão digital tem sido comumente utilizado pelo setor público para compor abordagens políticas de caráter populista, que se traduzem em uma espécie de nova solução para quase todas as dificuldades da sociedade atual, como pobreza, desigualdade social, problemas educacionais, injustiça social, desemprego, violência e criminalidade.

A questão da inclusão digital perpassa por uma discussão maior do verbo incluir e os conceitos derivados dele. Torna-se importante examinar os paradigmas ou dogmas do que se entende por "Sociedade da Informação," bem como sobre inclusão e exclusão.

A relação entre inclusão digital e inclusão social se mostra de forma ainda pouco esclarecida, por isso muitas vezes confusa e destoante se considerada a demanda social e os tipos de programa empreendidos pelo setor público. Em decorrência desse embate conceitual e pragmático, ou o próprio deslocamento dos objetivos essenciais nos tipos de inclusão considerados, torna-se necessário um melhor esclarecimento quanto aos fins que se destinam os planos e ações relacionados à inclusão digital e social, bem como a quem interessa e se destina tais planos.

A partir daí e em decorrência de uma série de questionamentos sobre a inclusão digital por parte de entes governamentais, este trabalho procura responder às seguintes questões de pesquisa: Que tipo de ações e programas o Portal de Inclusão Digital do Governo Federal Brasileiro tem criado e desenvolvido com 
o intuito de incluir digitalmente os cidadãos brasileiros? A que fim e para quem as ações empreendidas são criadas e direcionadas?

Como forma de responder a tais questionamentos, este estudo se propõe a apresentar uma discussão sobre inclusão digital e, especialmente, cumprir com o objetivo geral que é observar e analisar o Portal de Inclusão Digital do Governo Federal Brasileiro em termos das ações, projetos, programas e documentos de âmbito federal, apontando seus objetivos e público-alvo.

A metodologia aplicada se baseia na perspectiva da pesquisa qualitativa. A coleta de dados se deu a partir de técnicas de observação direta e análise de documentos, sendo efetuada por navegação orientada, conforme explicitada na seção de metodologia. Os resultados e a discussão sobre os dados encontrados são apresentados como forma de verificar o objetivo antes mencionado.

Entre as contribuições deste estudo, ressaltam-se as discussões sobre o hiato existente entre o discurso e a prática de gestores públicos em relação à inclusão digital, haja vista que os dados apresentados demonstram aspectos de superficialidade e inconsistências na política pública voltada para a inclusão, que pode ser observada ao navegar no portal investigado e no descolamento entre a realidade observada e as proposições apresentadas pelo governo federal. A partir dessas discussões, este estudo pode contribuir de modo empírico para a ação de gestores públicos e governos na implementação de políticas públicas voltadas para a inclusão digital, bem como apoiar outros estudos sobre esse tema no Brasil.
Como forma de organizar a discussão realizada neste estudo, ele se divide em cinco seções. Além desta introdução, a segunda seção apresenta a fundamentação teórica na qual este trabalho se apoia, que aborda inclusão digital e inclusão social, assim como sua aplicação no Brasil. Na terceira seção é apresentada a metodologia aplicada no estudo e, na quarta, apresentam-se os resultados encontrados e a discussão. Na sequência, a última seção expõe as considerações finais a que foram possíveis se chegar a partir do trabalho.

\section{Fundamentação teórica}

Esta seção apresenta uma breve revisão da literatura que respalda e dá base teórica para a discussão apresentada ao fim deste. O enfoque da primeira subseção se dá sobre a inclusão digital associada à inclusão social e, na segunda, o enfoque recai sobre a inclusão digital no caso específico do Brasil, conforme se verá adiante.

\subsection{Inclusão digital e inclusão social}

A inclusão digital é um tema polêmico na academia, pois seus significados e objetivos produzem intensos debates. As polêmicas mais comuns e que não encontram consenso entre os teóricos são as que envolvem as questões relativas ao treinamento de pessoas para o uso dos recursos tecnológicos de comunicação digital, bem como a democratização do acesso a tais tecnologias (Bonilla \& Oliveira, 2011).

De acordo com Bonilla e Pretto (2011), existem dois tipos de inclusão: espontânea e induzida. A espontânea é uma inserção compulsória das pessoas na sociedade da 
informação, a exemplo do uso de cartões eletrônicos de débito e crédito, de smart cards em ônibus, da operação em caixas eletrônicos, do envio de imposto de renda pela internet, votação via urna eletrônica, acesso eletrônico a vários órgãos públicos, check in pela Web em viagens de avião, uso de SMS (Short Message Service) em serviços via telefone celular, entre outros. A induzida, por sua vez, é o resultado de um trabalho educativo e de políticas públicas que permitem à parcela da população excluída o uso e os benefícios da sociedade da informação. Esta segunda é o que se conhece por projetos de inclusão digital.

Contudo, muitas das pessoas usam essas tecnologias de forma incipiente e não sabem retirar para si proveito com qualidade de todos os benefícios culturais, sociais e econômicos que os instrumentos e ferramentas eletrônicas de comunicação lhes oferecem (Mattos, 2005, \& Duarte, 2012). Para esses indivíduos, o desafio dos projetos de inclusão digital está na tentativa de fazer com que eles sejam induzidos e fortalecidos pela dimensão cidadã e educacional, já que a inclusão é um problema cultural e não apenas econômico ou cognitivo (Bonilla \& Pretto, 2011, \& Alonso et al., 2010).

A cultura da mobilidade invade a sociedade e os dispositivos móveis, tais como celulares, smartphones, netbooks ultrabooks e tablets, e exige um pensar diferente quanto à potencialização da reciprocidade entre a mobilidade física e a mobilidade informacional. Fala-se agora de uma era do Pós-PC, ou seja, o computador conectado ou coletivo, no qual a computação em rede passa a ser o grande valor deste início do século XXI, na era da computação ubíqua, móvel, hiperlocal e das mídias locativas e da internet das coisas (Bonilla \& Pretto, 2011).

Dessa forma, é possível observar com clareza os novos formatos culturais que surgem e que devem ser idealizados em projetos de inclusão digital, os quais se caracterizam pela possibilidade de produzir e distribuir informações. Essas possibilidades são instrumentos importantes de luta política, de organização e mobilização social e de circulação livre de informação, como foi o caso dos recentes levantes populares no mundo (Bonilla \& Pretto, 2011), incluindo o Brasil.

Seguindo esse prisma, a inclusão digital deve ser pensada como uma questão de direito à ação política e ser objeto de ações governamentais, tal como o governo móvel, no qual a emergência de novos instrumentos de inclusão digital amplia os quatro capitais básicos: social, cultural, intelectual e técnico (Bonilla \& Pretto, 2011). Entretanto, as diversas ações desenvolvidas pelos programas de inclusão digital, em geral, são ações propostas de forma isolada, desarticuladas das outras políticas públicas, e não consideram a complexidade dos processos vividos pelas comunidades, como se a dinâmica social não fosse resultante de nossas ações, interações e concepções, em relação e movimento. Tudo isso, como se a sociedade não fosse composta por sujeitos ativos e que não houvesse o problema das desigualdades, que no caso do Brasil são amplas, o que torna a revolução tecnológica importante instrumento de inclusão social ou não (Mattos, 2005; Tramontin e Borges, 2007; Bonilla \& Oliveira, 2011).

O termo inclusão digital tem sido comumente utilizado pelo setor público para compor 
abordagens políticas de atitude populista, que se traduzem em uma nova solução para quase todas as dificuldades da sociedade atual: pobreza, desigualdade social, problemas educacionais, injustiça social, desemprego, violência, criminalidade, entre outros (Bonilla \& Oliveira, 2011; Duarte, 2012).

Em sentido mais amplo, o termo indica que as pessoas que frequentam os telecentros e infocentros devem apoderar-se das tecnologias digitais e, dessa forma, atuar com autonomia e independência. No entanto, isso não tem acontecido, pois os modos de gestão dos espaços citados são, em geral, centralizadores e impõem regras e normas vinculadas aos projetos de utilização das tecnologias, submetendo as pessoas ao uso passivo e limitado dos recursos das tecnologias de comunicação (Bonilla \& Oliveira, 2011; Duarte, 2012). Portanto, o estado não deve separar as propostas de informatização pública das políticas de ampliação da cidadania por meio eletrônico (Tramontin e Borges, 2007).

Como asseveram Bonilla e Oliveira (2011, p. 34):

Registros e declarações que afirmam que as ações ditas de inclusão digital estimulam a geração de emprego e renda, diante dos complexos problemas estruturais associados ao desemprego, são, no mínimo, simplistas e reducionistas.

Que as habilidades comprovadas ou certificadas do uso de aplicativos básicos melhoram as chances de conseguir emprego na atualidade é fato. No entanto, vale ressaltar que o mercado de trabalho exige cada vez mais qualificação profissional ampliada e associada ao nível educacional dos sujeitos, já que a destreza no uso das tecnologias digitais é apenas um dos requisitos exigidos.

A questão da inclusão digital perpassa pela discussão do verbo incluir e os conceitos derivados dele. André Lemos (2003), citado por Bonilla e Oliveira (2011), propõe examinar os paradigmas ou dogmas do que se entende por "Sociedade da Informação", inclusão e exclusão, pois a inclusão significa, na maioria das vezes, oferecer condições de acesso às tecnologias para as pessoas, sem abranger os processos cognitivos questionadores, tão necessárias ao desenvolvimento social humano.

É necessário, portanto, avaliar a forma de realização de cursos básicos de informática para a população de baixa renda, para que a inclusão de cidadãos, produtos ou informações ocorra de forma plena e que as pessoas possam participar ativamente como seres éticos, autônomos e com poder de decisão, pois não basta estar à frente de um computador para superar uma condição de exclusão (Lévy, 1999; Bonilla \& Oliveira, 2011; Duarte, 2012). Afinal, a discussão dos significados, sentidos, concepções, ações e formulações políticas da inclusão digital apresentam muitas questões com lacunas, abordagens superficiais e incipientes, principalmente quando se apresentam os resultados obtidos em projetos e programas relacionados ao tema (Bonilla \& Oliveira, 2011).

Observa-se que a disseminação de telecentros ou infocentros parece ser a principal estratégia para realizar a inclusão digital no Brasil. Esses locais mobilizam amplos investimentos e esforços e geram movimentos e fluxos, todavia os resultados e suas impli- 
cações são pouco avaliados, em especial quanto aos aspectos qualitativos, sociais e políticos. Inclusive, um sensor negativo que pode ser enfatizado com relação ao uso dos espaços é o da pesquisa TIC domicílios e usuários ocorrida em 2009 (CGI.br, 2010), a qual apresentou o seguinte quadro: $4 \%$ dos usuários de internet no Brasil utiliza os centros públicos de acesso gratuito; em contrapartida, $45 \%$ usam os centros públicos de acesso pago (Bonilla \& Oliveira, 2011).

Desse modo, há necessidade de uma reflexão sobre o rumo das políticas e ações que se intitulam inclusão digital, pois as lacunas apontadas nos conceitos também existem nos modos de gestão e operacionalização dos projetos. Não que faltem as questões culturais e educacionais nas discussões, porém quase sempre tratadas insuficientemente (Bonilla \& Oliveira, 2011).

Uma pessoa pode ser um excluído digital por três grandes formas: a) não tem acesso à rede de computadores; b) tem acesso ao computador, mas com capacidade técnica muito baixa; c) está conectado à rede e não sabe o que acessar, qual informação procurar, como relacionar um assunto com outro e como utilizar tudo isso para seu benefício. A terceira é a mais grave de todas, porque aprofunda a exclusão que é de educação e de cultura (Castells, 2005). Ou seja, é necessário ir além da perspectiva técnica e do mero acesso, permitindo que a inclusão digital seja também social e aborde os aspectos educacionais, culturais e de cidadania ativa com maior intensidade (Bonilla \& Oliveira, 2011; Santos \& Hetkowski, 2008).

Contudo, essa perspectiva de inclusão social vinculada à digital parece estar longe das formulações políticas e ações sociais direcionadas à suposta ampliação do acesso às tecnologias para a população desfavorecida. A inclusão digital, dessa forma, torna-se insuficiente para abarcar todas as potencialidades da Tecnologia da Informação e Comunicação (TIC) na organização das pessoas para a transformação social (Bonilla \& Oliveira, 2011).

Debater inclusão digital requer que se discuta também as políticas que abarquem o acesso às novas TICs, bem como os elementos de inclusão social em sentido amplo: economia política, mercado, hábitos sociais, profissões, entre outros (Duarte, 2012). Afinal, a "inclusão digital não é alcançada apenas quando se dá computadores ou acesso à internet, mas quando o indivíduo é colocado em um processo mais amplo de exercício pleno de sua cidadania" (Bonilla \& Pretto, 2011, p. 16). Assim, os Governos - municipal, estadual e federal -, por meio de políticas públicas eletrônicas - e-government - ao longo dos anos estão incluindo digitalmente um maior número de cidadãos, já que interferem em todos os canais de inclusão digital (Bernardi e Dias, 2008).

Pensada de forma mais complexa, a inclusão digital estimula os quatro capitais básicos por meio da educação de qualidade, da facilidade de acesso aos hardwares de comunicação global e da internet, pela geração de empregos, entre outros elementos que transformam as condições da existência humana. Desse modo, os programas de inclusão digital devem criar condições para a formação global das pessoas a fim de atingir a inclusão social (Bonilla \& Pretto, 2011; Alonso et al., 2010). 
Conforme se nota na discussão, há uma série de aspectos políticos e sociais embutidos na questão da inclusão digital, o que demonstra claramente o forte vínculo que se cria entre o papel dos governos e os benefícios sociais inerentes à inclusão que se pretende a partir do avanço da democratização do acesso e da capacitação dos cidadãos junto às tecnologias comunicacionais e informacionais. Com base nesse entendimento, a discussão na próxima subseção abordará como a inclusão digital tem sido conduzida no caso específico do Brasil.

\subsection{Inclusão digital no Brasil}

Em 1998, foram dados os primeiros passos para o Brasil integrar a sociedade da informação. As discussões entre o Conselho de Ciência e Tecnologia (CCT) e o Instituto Brasileiro de Informação em Ciência e Tecnologia (IBICT) levaram ao Programa Sociedade da Informação. Nessa fase inicial, o Brasil procurou promover infraestrutura de informação com velocidade alta, aplicações avançadas, experimentos nas áreas das TICs e qualidade de serviços (Neves \& Gomes, 2008).

Já em 1999, o tema inclusão digital passa a se fazer presente na política pública brasileira, quando o Governo Federal institucionalizou o Programa Sociedade da Informação no Brasil (Socinfo), pelo Decreto $\mathrm{n}$. 3.294/99. A pauta sobre Inclusão Digital no Brasil apareceu na agenda política do ano de 2000, quando lançou o Livro Verde - Sociedade da Informação no Brasil (Bonilla \& Oliveira, 2011).

O Programa Sociedade da Informação, exposto no Livro Verde, listava alguns itens primordiais: relevância da internet para o comércio eletrônico - ampliação, diversificação e aperfeiçoamento; comunicação mais rápida e menos dispendiosa para as pequenas e médias empresas; criação de um ambiente inovador; geração de novas oportunidades de trabalho; universalização do acesso à educação (Neves \& Gomes, 2008; Carvalho, 2003). Para o Programa, a inclusão digital e, por conseguinte, a inclusão social, ocorreriam por meio da oferta de computadores e aplicativos, acesso à internet, capacitação, treinamento e interação para a população carente sem acesso a esses itens (Silva Neto \& Carvalho, 2008). Nas áreas de Inclusão Digital e Universalização de Serviços e Identidade Cultural, o Socinfo estava pronto para implantar em todo país 15 mil Bibliotecas Digitais quando foi descontinuado no ano de 2003.

Em 2000, o Ministério do Planejamento, Orçamento e Gestão criou o Governo Eletrônico (GovBr) para universalizar serviços e permitir ao Governo estar ao alcance de todos, bem como para criar uma infraestrutura avançada de internet. No GovBr, a inclusão digital foi tratada como um elemento importante da política de governo eletrônico a ponto de se configurar na política universal, ou seja, como direito de cidadania e objeto de políticas públicas para sua promoção (Silva Neto \& Carvalho, 2008).

A partir do GovBr foi instituído, em 2003, o Comitê Técnico de Inclusão Digital, no âmbito do Comitê Executivo do Governo Eletrônico, o qual:

tem competência para estabelecer as diretrizes gerais de gestão e aplicação dos recursos financeiros destinados ao Pro- 
grama de Inclusão Digital, assim como acompanhar e monitorar a implementação e desempenho dos projetos do programa (Brasil, 2013b, sp).

O Programa Nacional de Inclusão Digital brasileira foi instituído em 2005, por meio da Lei n. 11.196/05, nos seus artigos de 28 a 30, os quais estabelecem a redução para zero de alíquotas da Contribuição para o PIS/Pasep e da Cofins incidentes sobre a receita bruta de venda a varejo sobre os equipamentos tecnológicos. Posteriormente a essa primeira medida, foi criado o Comitê Gestor do Programa de Inclusão Digital (CGPID), contudo, somente foi instituído pelo Decreto n. 6.948 , de 25 de agosto de 2009.

Os objetivos do Programa são:

proporcionar à população menos favorecida o acesso às facilidades da tecnologia da informação, capacitando jovens para o mercado de trabalho, bem como trabaIhadores em práticas relacionadas com a informática e focar a implementação de Telecentros, no qual, o público-alvo receberá capacitação em informática básica e navegação na rede mundial de computadores, o que contribuirá para a melhoria da educação e aperfeiçoamento de mão de obra (Brasil, 2013b, sp.)

O Ministério da Ciência e Tecnologia (MCTI) é o responsável pelo Programa e indica em sua página eletrônica que, em 2008, foram aprovados 331 projetos, dos quais $R \$ 5,1$ milhões foram destinados a projetos de execução direta para Inclusão Digital e R \$ 2,3 milhões para o Programa de Telecentros. Observa-se, porém, que muitas informações e até hospedagens dos principais sites do Programa estão a cargo do Ministério das Comunicações.

Os projetos indicados pelo MCTI foram distribuídos regionalmente conforme ilustra a Figura 1 e os principais resultados de 2010 apresentados no site do Ministério são os informados na Figura 2.

Figura 1. Distribuição regional dos 331 projetos aprovados em 2008

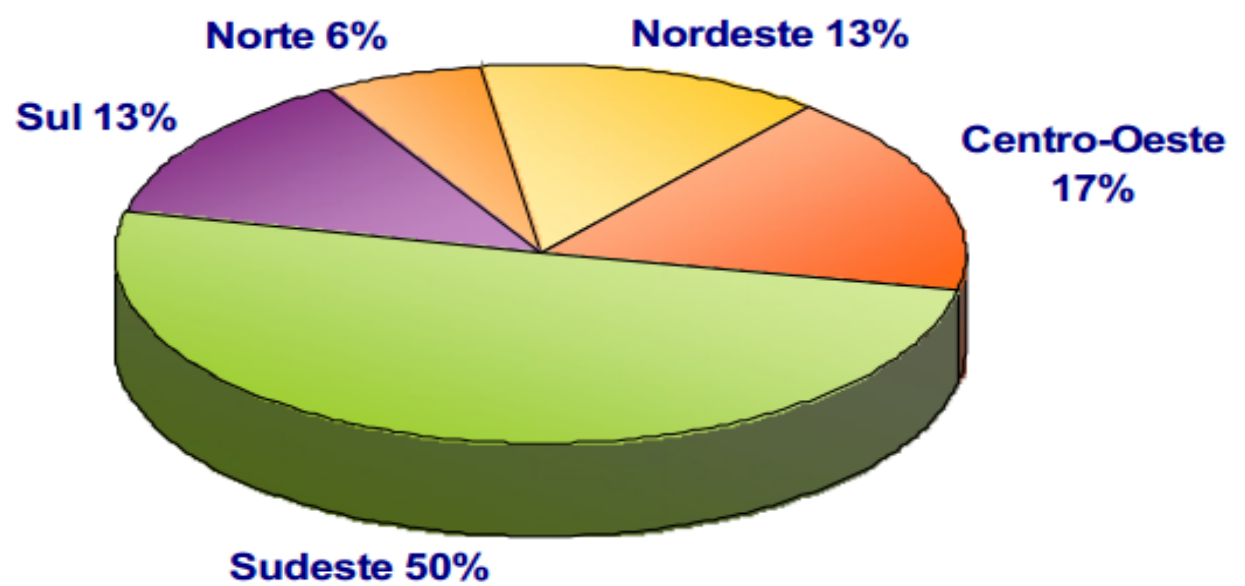

Fonte: MCTI (2013) 
Figura 2. Resultados atingidos pelo Programa Nacional de Inclusão Digital em 2010
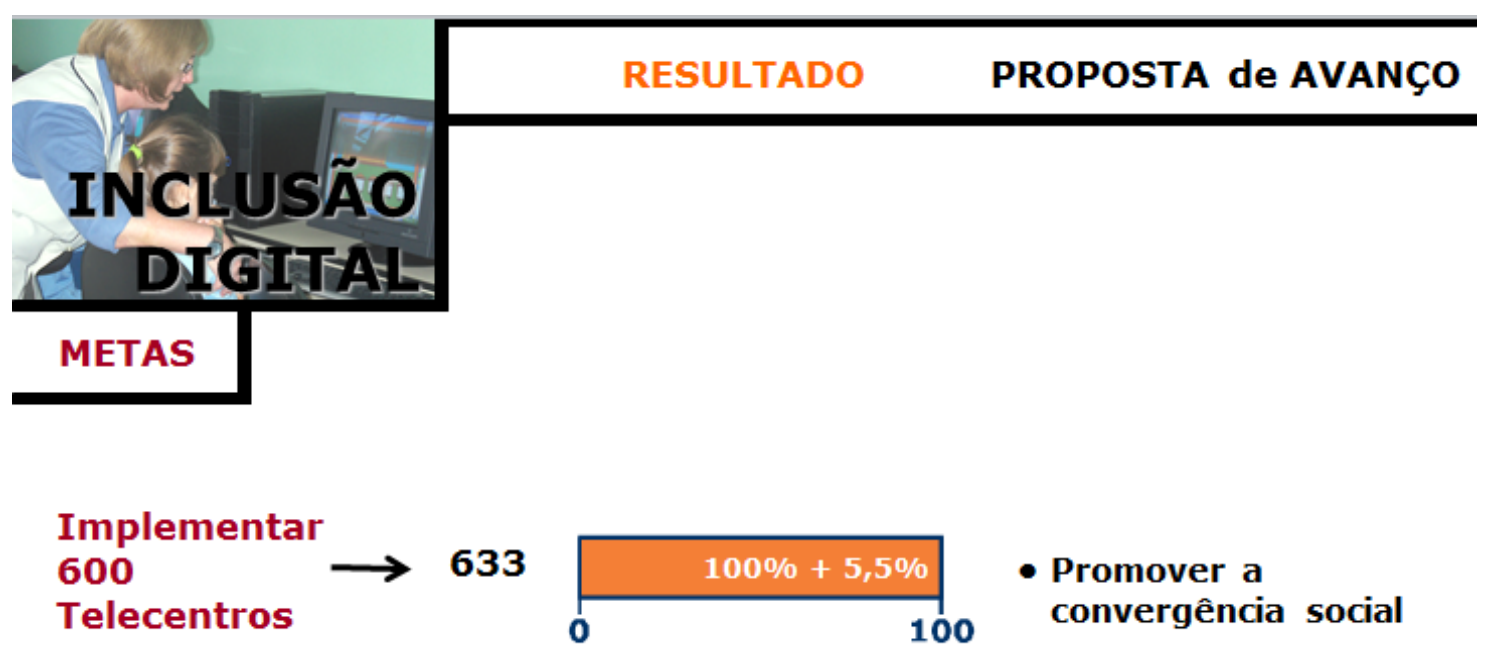

\section{Promover a} capacitação de monitores em informática

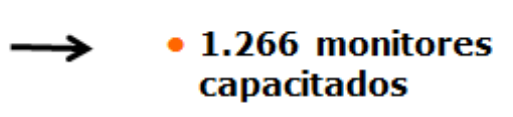
capacitados
- Dar continuidade

Fonte: MCTI (2013)

Martins e Lucas (2009) fizeram uma categorização dos programas de inclusão digital brasileiros de 2009. Como ela foi elaborada sob a perspectiva das concepções da competência informacional de Dudziak, permitiu visualizar os programas de forma específica e de acordo com sua ênfase, conforme apresentado no Quadro 1. 
Kleomara Gomes Cerquinho, Wellington Tavares, Ana Paula Paes de Paula, Irineu Amaro Vitorino

\begin{tabular}{|c|c|c|}
\hline Tipo de inclusão & Ênfase & Programas \\
\hline Inclusão Digital & $\begin{array}{ll}\text { Tecnologias de } \\
\text { informação e } \\
\text { comunicação }\end{array}$ & $\begin{array}{l}\text { a) Capacitação e oferecimento de infraestrutura tecnológica de uso coletivo: } \\
\text { - Governo Eletrônico Serviço de Atendimento ao Cidadão (Gesac) } \\
\text { - Computadores para a Inclusão } \\
\text { - Kits Telecentros } \\
\text { - Programa Nacional de Informática na Educação (Prolnfo) } \\
\text { - Pontos de Cultura - Cultura Digital } \\
\text { - Telecentros Banco do Brasil } \\
\text { - Centros de Inclusão Digital } \\
\text { - Serpro Cidadão } \\
\text { b) Oferecimento de equipamentos tecnológicos de forma individualizada: } \\
\text { - Cidadão Conectado - um computador para todos } \\
\text { - Programas Computador portátil para Professores } \\
\text { - Um Computador por Aluno (UCA), sendo que diferentemente dos dois citados antes, a aquisição } \\
\text { do computador não é feito por compra, mas sim por doação. }\end{array}$ \\
\hline $\begin{array}{l}\text { I n c I u s ã o } \\
\text { Informacional }\end{array}$ & $\begin{array}{l}\text { Processos } \\
\text { cognitivos }\end{array}$ & $\begin{array}{l}\text { - Centros Vocacionais Tecnológicos: aborda conteúdos informativos com maior profundidade, como } \\
\text { empreendedorismo, visando à difusão do conhecimento científico e tecnológico. } \\
\text { - Territórios Digitais: instrui as pessoas da própria comunidade a administração da Casas Digitais, por } \\
\text { meio de conteúdos de gestão. } \\
\text { - Programa Estação Digital: capacita as pessoas da própria comunidade a atuar como educadores } \\
\text { sociais, abrangendo desde conteúdos básicos, como navegação na internet, a conteúdos densos - } \\
\text { introdução à Sociedade da informação e Governo Eletrônico. }\end{array}$ \\
\hline Inclusão Social & $\begin{array}{l}\text { Construção da } \\
\text { cidadania }\end{array}$ & $\begin{array}{l}\text { - Casa Brasil: o projeto apresenta-se com infraestrutura completa de equipamentos e recursos } \\
\text { humanos capacitados para mobilizar o exercício da cidadania dos indivíduos que atende. } \\
\text { - Maré - Telecentros de Pesca: atua com o intuito de inserir o segmento pesqueiro artesanal brasileiro } \\
\text { na sociedade da informação, por meio do uso intenso das TICs. } \\
\text { - Telecentros de Informação e Negócio (TIN): proporciona ao segmento das microempresas e } \\
\text { empresas de pequeno porte alfabetização digital, capacitação empresarial e tecnológica. Utiliza-se } \\
\text { dos recursos do Telecentro para modificar o perfil de seus usuários - de consumidores de informação } \\
\text { para produtores e disseminadores de conhecimento. } \\
\text { - Quiosque Cidadão: atua em comunidades da Região Integrada de Desenvolvimento do Distrito } \\
\text { Federal e Entorno, por meio da presença de um Telecentro que atua provendo conteúdos específicos } \\
\text { a essa comunidade. }\end{array}$ \\
\hline
\end{tabular}

Quadro 1. Programas de inclusão digital do governo federal sob a perspectiva das concepções da competência informacional de Dudziak

Fonte: Adaptado de Martins \& Lucas, 2009 
Na concepção dos autores, apenas o Programa ONID não se encaixa nesse quadro por ser uma ferramenta de acompanhamento e mensuração das iniciativas em inclusão digital, como também disseminador de informações por meio de banco de referência. No entanto, esse programa estava incluído no Portal de Inclusão Digital do Governo Federal, portanto faz parte do estudo (Martins \& Lucas, 2009).

Fato muito relevante para este estudo ocorreu em 2006, quando foi criado o Portal de Inclusão Digital, o qual passou a aglutinar notícias e informações sobre os vários programas de facilitação do acesso a computadores e internet para a sociedade (Brasil, 2013b).

$\mathrm{Na}$ "Agenda de Eventos" do site do MCTI não constavam os eventos do ano de 2013, período em que ocorreu esta pesquisa, nem dos anos anteriores. Já em relação aos espaços disponibilizados na internet, há um grupo de 15 sites relacionados à Inclusão Digital no Brasil, os quais são indicados no Portal Governo Eletrônico Brasileiro (Gov.br, 2013), conforme indicados no Quadro 2:

\begin{tabular}{|c|c|}
\hline Site & Endereço eletrônico \\
\hline Inclusão Digital & www.inclusaodigital.gov.br \\
\hline Banda Larga nas Escolas & $\begin{array}{l}\text { http://portal.mec.gov.br/index.php?option=com_content\&view=article\&id=15808:programa- } \\
\text { banda-larga-nas-escolas\&catid=193:seed-educacao-a-distancia }\end{array}$ \\
\hline Casa Brasil & http://www.casabrasil.gov.br \\
\hline Computadores para Inclusão & http://www.computadoresparainclusao.gov.br \\
\hline Oficina para Inclusão Digital & http://oficina.inclusaodigital.gov.br \\
\hline Observatório de Inclusão Digital & http://www.onid.org.br/portal \\
\hline $\begin{array}{l}\text { Projeto Cidadão Conectado - } \\
\text { Computador para Todos }\end{array}$ & http://www.computadorparatodos.gov.br \\
\hline Programa Gesac & http://www.gesac.gov.br \\
\hline $\begin{array}{l}\text { Programa de Implantação de Salas de } \\
\text { Recursos Multifuncionais }\end{array}$ & $\begin{array}{l}\text { http://portal.mec.gov.br/index.php?option=com_content\&view=article\&id=14187:programa-de- } \\
\text { implantacao-de-salas-de-recursos-multifuncionais-2008\&catid=192:seesp-esducacao-especial }\end{array}$ \\
\hline Programa de Inclusão Social e Digital & http://www.mct.gov.br/index.php/content/view/77601.html \\
\hline Prolnfo Integrado & $\begin{array}{l}\text { http://portal.mec.gov.br/index.php?option=com_content\&view=article\&id=13156:proinfo- } \\
\text { integrado\&catid=271:seed }\end{array}$ \\
\hline Programa Telecentros Comunitários & http://www.mc.gov.br/inclusao-digital-mc/telecentros \\
\hline Telecentros BR & http://www.inclusaodigital.gov.br/telecentros \\
\hline Territórios Digitais & http://comunidades.mda.gov.br/dotlrn/clubs/territriosdigitais/one-community?page_num=0 \\
\hline Um Computador por Aluno & http://www.fnde.gov.br/index.php/laptops-educacionais \\
\hline
\end{tabular}

Quadro 2. Sites relacionados à Inclusão Digital no Brasil

Fonte: Brasil (2013b) 
Como se pode notar, atualmente a inclusão digital está em plena discussão no Brasil com o Plano Nacional de Banda Larga (PNBL), o qual pretendia expandir a banda larga a 40 milhões de domicílios brasileiros até 2014 (Brasil, 2013a), oferecendo internet de alta velocidade e baixo custo para toda a população.

\section{Metodologia}

Este estudo se baseia em uma pesquisa realizada sob a perspectiva da pesquisa qualitativa, a qual se mostra de forma adequada para a compreensão da natureza de fenômenos sociais, possibilitando compreender situações e significados de forma apurada (Richardson et al., 2011, p. 79). Nesse tipo de pesquisa não são estabelecidas regras precisas, mas sim uma estruturação prévia para melhor orientação do pesquisador em relação ao contexto e objeto de pesquisa. Contudo, apesar da flexibilidade apresentada, é necessário que o pesquisador mantenha coerência com os métodos e teorias selecionados no estudo e com os dados e a análise (Marconi \& Lakatos, 2007).

O objeto de pesquisa deste estudo, realizado em julho de 2013, foi o Portal de Inclusão Digital do Governo Executivo Brasileiro. Nessa investigação, foram analisados ações, projetos, programas e documentos em âmbito Federal, apontando seus objetivos e públicos-alvo.

O plano de coleta de dados foi estabelecido a partir de duas técnicas, mencionadas a seguir, que propiciaram a obtenção dos dados necessários para o estudo.

Observação direta: foi escolhida neste es- tudo por possibilitar o registro de situações que, por mais banais que possam parecer, dão indicações de como os significados são construídos no contexto analisado (Bogdewic, 1999). Diante disso, a pesquisa aconteceu mediante as observações feitas pelos pesquisadores no Portal de Inclusão Digital do Governo Federal.

Coleta de dados: foi possível realizá-la partir de técnicas de observação, a qual se mostra como elemento elementar em pesquisas científicas e requer o uso dos sentidos nas atividades de coleta de dados de forma direta no contexto estudado (Marconi \& Lakatos, 2007). Esse tipo de técnica, talvez pela possibilidade de ser aplicada como base em qualquer pesquisa no campo social, permite obter informações sobre novos fenômenos e entender novos contextos, o que pode ocasionar a descoberta de resultados inesperados (Richardson et al., 2011).

Portanto, o estudo se baseou na proposta de observação direta apresentada por Silva (2009). Dessa forma, a observação direta na unidade de análise se deu (1) pela navegação orientada nos sites escolhidos para a pesquisa; (2) por meio de testes e simulações das ferramentas on-line que foram analisadas.

Como forma de realizar a observação direta, foi feita uma navegação orientada, a qual se mostrou como a principal fonte dos dados, sendo definida como um modo de correr links e páginas, assim como obter critérios e parâmetros para qualificar os objetos catalogados ao longo da navegação, de acordo com as categorias encontradas.

Na definição de como pesquisar o assunto, 
optou-se por escolher a seguinte divisão no âmbito federal: a) Ações, projetos e programas; b) Documentos. Nesse sentido serão descritos os objetivos e públicos-alvo em quadros específicos para o alcance do objetivo desta pesquisa.

Já em relação à análise de documentos, a apreciação deles inclui documentos históricos, leis, declarações e relatos das pessoas sobre diversos contextos. Além disso, outros elementos podem compor os dados para a análise, tais como fotografias e outras possibilidades de acordo com o contexto em estudo (May, 2004). No caso deste estudo e devido à sua particularidade em termos documentais, as fontes de informação estão disponíveis no Portal de Inclusão Digital no ciberespaço. As informações foram obtidas por meio das ferramentas que um site ou software leitor de textos disponibiliza.

\section{Caso e discussão}

O Portal Inclusão Digital conta com as seguintes divisões pertinentes à Inclusão Digital: Institucional; Ações e Programas; Documentos; Comunicação, e Fale Conosco. Foram escolhidos "Ações e Programas" e "Documentos" de âmbito federal para atender aos objetivos desta pesquisa, no intuito de saber para quê e para quem é direcionado o Programa Nacional de Inclusão Digital do Governo Federal.

Dessa forma, o Portal foi analisado e dividido em: a) Ações, projetos e programas; b) Documentos. Após a identificação das informações, foi criado um quadro indicando para quê e para quem foram direcionadas as ações, projetos, programas e documentos.

\subsection{Ações, projetos e programas}

As informações pertinentes a essas divisões são indicadas na Figura 3.

Figura 3. Ações e Programas do Programa Nacional de Inclusão Digital

\begin{tabular}{|c|c|c|c|}
\hline GONERNO FEDERAL & GONERNO ESTADUAL & GOVERNO MUNICIPAL & SOCIEDADE CIVIL \\
\hline 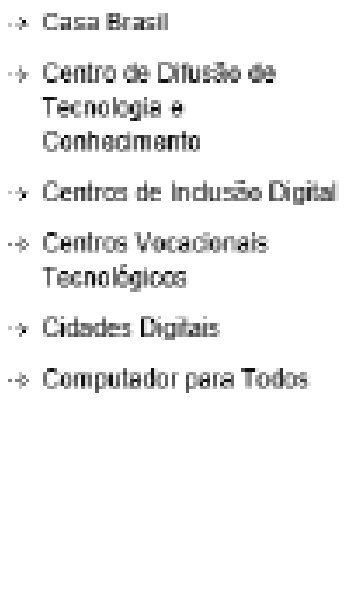 & 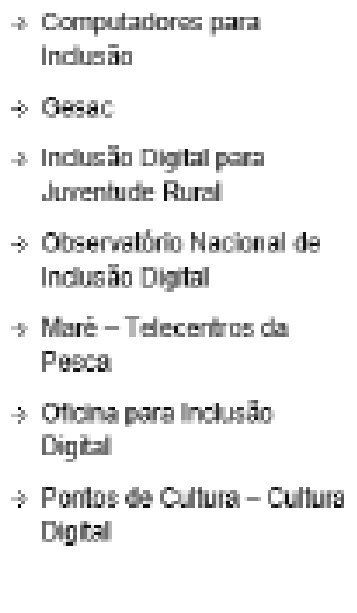 & 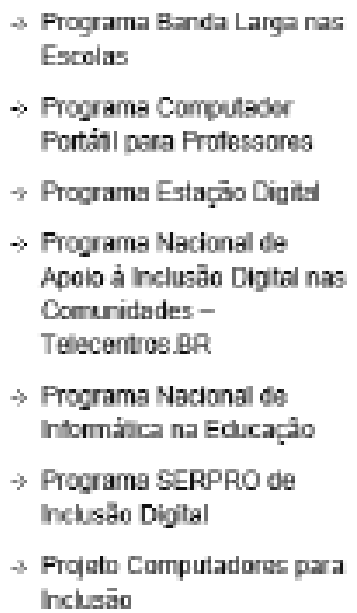 & 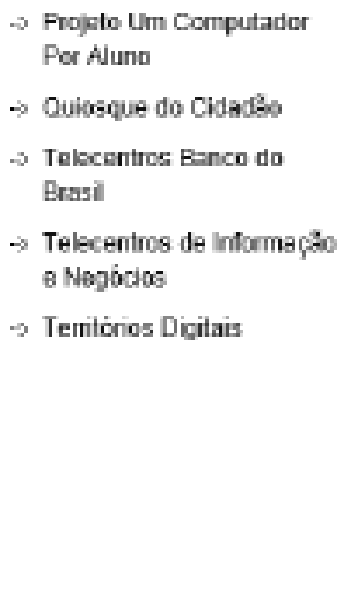 \\
\hline
\end{tabular}

Fonte: Portal Inclusão Digital (2013) 
A Figura 3 apresenta Ações, Projetos e Programas das esferas federal, estadual, municipal e da sociedade civil. Neste estudo serão verificados aqueles de âmbito federal devido ao objetivo principal desta pesquisa.

O Projeto Casa Brasil é citado por meio de um link no Portal, mas está sem informações (dados ausentes no Portal e encontrados no endereço eletrônico: http://caminhoinclusaodigital.wikidot.com/projetos-de-inclusao-digital). O Projeto é um Programa de Inclusão Digital da Secretaria de Ciência e Tecnologia para Inclusão Social do Ministério da Ciência e Tecnologia (Secis - MCT), cujo propósito é levar às comunidades localizadas em áreas de baixo IDH computadores e conectividade, priorizando ações em tecnologias livres aliadas a cultura, arte, entretenimento, articulação comunitária e participação popular. Cada unidade do Projeto abrigaria um telecentro com software livre e no mínimo mais dois módulos à escolha: biblioteca popular, auditório, estúdio multimídia, oficina de produção de rádio, laboratório de popularização da ciência ou oficina de manutenção de equipamentos de informática, e um espaço para atividades comunitárias. Também pode vincular um módulo de inclusão bancária nas localidades em que for possível. Segundo informações do site "Caminhos para Inclusão Digital", atualmente são 74 unidades em funcionamento, com capacitação de mais de 1.000 pessoas nas 37 oficinas livres oferecidas a partir da plataforma de educação a distância construída pelo projeto.

O Projeto Centro de Difusão de Tecnologia e Conhecimento (CDTC) também é apresentado no Portal, mas sem informações (dados ausentes no Portal e encontrados no endereço eletrônico: www.4linux.com.br/clientes/ projeto-cdtc-centro-difusao-tecnologia-conhecimento.html). O Projeto é um acordo de cooperação técnica entre o Governo Brasileiro e a IBM Brasil para fomentar o uso do Linux com padrões abertos entre os órgãos públicos federais. Nesse Projeto foram treinados 785 técnicos do Ministério da Educação e de outras Secretarias para aprenderem a instalar e utilizar o Linux e outros softwares livres.

Os Centros de Inclusão Digital - CIDs (dados ausentes no Portal e encontrados no endereço eletrônico: http://caminhoinclusaodigital.wikidot.com/projetos-de-inclusao-digital) fazem parte de uma ação que serve de instrumento de promoção da inclusão digital. Sob a responsabilidade da Secretaria de Ciência e Tecnologia para Inclusão Social (Secis), os CIDs têm como objetivo "proporcionar à população menos favorecida o acesso às tecnologias de informação, capacitando-a na prática das técnicas computacionais, voltadas tanto para o aperfeiçoamento da qualidade profissional quanto para a melhoria do ensino", de acordo com informações dessa secretaria.

Os Centros Vocacionais Tecnológicos também é citado no Portal, mas está sem informações (dados ausentes no Portal e encontrados no endereço eletrônico: http://www. mct.gov.br/index.php/content/view/77600. html). Os centros são unidades de ensino e profissionalização, voltados para a difusão do acesso ao conhecimento científico e tecnológico e dos conhecimentos práticos na área de serviços técnicos, além da transferência de conhecimentos tecnológicos na área de processo produtivo. Sob a responsabilidade do MCTI, está atualmente com um Programa de Implementação e Modernização, ob- 
jetivando consolidar e expandir o programa para fortalecer a rede nacional de difusão e popularização da Ciência e Tecnologia, assim como ampliar a oferta de pontos de acesso ao conhecimento científico e tecnológico. Seu público-alvo é amplo.

Cidades Digitais é um projeto que visa possibilitar a modernização da gestão das cidades com a implantação de infraestrutura de conexão de rede entre os órgãos públicos e de aplicativos com o objetivo de meIhorar a gestão e o acesso da comunidade aos serviços de governo. As informações dispostas no Portal Inclusão Digital estão desatualizadas. Segundo o Ministério das Comunicações (www.mc.gov.br/inclusao-digital/acoes-e-programas/cidades-digitais), as cidades que recebem essa estrutura são selecionadas por meio de edital. A primeira seleção ocorreu em 2012 e 80 municípios foram contemplados. Em 2013, o projeto Cidades Digitais foi incluído no Programa de Aceleração do Crescimento (PAC) do Governo Federal, o que assegurou um reforço de R\$ 100 milhões no orçamento de 2013. Nesta segunda etapa, puderam se inscrever cidades de até 50 mil habitantes, distantes até $50 \mathrm{~km}$ do backbone (rede principal) da Telebrás ou que tivessem compromisso firmado com operadoras privadas para conexão à internet. $O$ projeto conta, entre outros, com a parceria do Ministério do Planejamento, da Telebrás, do Inmetro e do BNDES. A rede das Cidades Digitais é composta por um anel de fibra óptica que interliga os órgãos públicos locais. Empresas integradoras, contratadas por meio de pregão eletrônico, são responsáveis pelo fornecimento de equipamentos, serviços de instalação, suporte técnico e capacitação da administração municipal.

O projeto Computador para Todos foi instituído entre 2005 e 2008, com o objetivo de reduzir os preços dos computadores para facilitar o acesso. O Governo Federal criou linhas de financiamento pela Caixa Econômica Federal (CEF) para ajudar os cidadãos a comprar computadores. O primeiro foi descontinuado na prática e o segundo perdeu a importância diante da redução de preços promovida pelo próprio mercado (Bonilla \& Pretto, 2011). O projeto tinha como principal objetivo promover a inclusão digital, oferecendo ao consumidor a possibilidade de aquisição, em condições facilitadas, de produtos de informática constituídos de computadores, programas de computador (softwares) neles instalados e de suporte e assistência técnica necessários.

Diante do que se apresenta, elaborou-se - Quadro 3, que informa para quê e para quem as ações, projetos e programas de âmbito federal foram feitas. 
Kleomara Gomes Cerquinho, Wellington Tavares, Ana Paula Paes de Paula, Irineu Amaro Vitorino

\begin{tabular}{|c|c|c|}
\hline $\begin{array}{c}\text { Ação/Projeto/ } \\
\text { Programa }\end{array}$ & $\begin{array}{l}\text { Para quê } \\
\text { (objetivo) }\end{array}$ & $\begin{array}{l}\text { Para quem } \\
\text { (público-alvo) }\end{array}$ \\
\hline Projeto Casa Brasil & $\begin{array}{l}\text { Levar computadores e conectividade, priorizando } \\
\text { ações em tecnologias livres aliadas a: cultura, } \\
\text { arte, entretenimento, articulação comunitária e } \\
\text { participação popular. }\end{array}$ & Comunidades localizadas em áreas de baixo IDH \\
\hline Projeto CDTC & Fomentar o uso do Linux e padrões abertos. & Órgãos públicos federais \\
\hline $\begin{array}{l}\text { Centros de Inclusão } \\
\text { Digital - CID }\end{array}$ & $\begin{array}{l}\text { Promover a inclusão digital, proporcionando o } \\
\text { acesso às tecnologias de informação para capacitar } \\
\text { as pessoas na prática das técnicas computacionais, } \\
\text { tanto no aperfeiçoamento da qualidade profissional } \\
\text { quanto para a melhoria do ensino. }\end{array}$ & População menos favorecida \\
\hline $\begin{array}{l}\text { Centros Vocacionais } \\
\text { Tecnológicos }\end{array}$ & $\begin{array}{l}\text { Difundir o acesso ao conhecimento científico } \\
\text { e tecnológico, conhecimentos práticos na área } \\
\text { de serviços técnicos, além da transferência de } \\
\text { conhecimentos tecnológicos na área de processo } \\
\text { produtivo. }\end{array}$ & $\begin{array}{l}\text { Adolescentes; filhos de pequenos agricultores e } \\
\text { trabalhadores rurais da comunidade a ser assistida; } \\
\text { proprietários de pequenas propriedades; comunidade } \\
\text { ribeirinha; pessoas que integram programas } \\
\text { educacionais e tecnológicos; jovens e adultos com } \\
\text { interesse em serem capacitados profissionalmente, } \\
\text { bem como em terem o primeiro contato com a } \\
\text { informática; adultos interessados em sua requalificação } \\
\text { profissional. }\end{array}$ \\
\hline Cidades Digitais & $\begin{array}{l}\text { Possibilita a modernização da gestão das cidades } \\
\text { com a implantação de infraestrutura de conexão } \\
\text { de rede entre os órgãos públicos, bem como de } \\
\text { aplicativos, com o objetivo de melhorar a gestão e } \\
\text { o acesso da comunidade aos serviços do governo. }\end{array}$ & $\begin{array}{l}\text { Municípios com até } 50 \text { mil habitantes, distantes até } 50 \\
\text { km da rede principal da Telebrás, ou com compromisso } \\
\text { firmado com operadoras privadas para conexão à } \\
\text { internet. }\end{array}$ \\
\hline Computador para Todos & $\begin{array}{l}\text { Possibilita a obtenção de um equipamento } \\
\text { computacional de qualidade, com sistema } \\
\text { operacional e aplicativos em software livre, que } \\
\text { atenda ao máximo às demandas do usuário, além de } \\
\text { permitir acesso à internet. }\end{array}$ & População que não tem acesso ao computador. \\
\hline
\end{tabular}

\section{Quadro 3. Para quê e para quem as Ações, Projetos e Programas de âmbito federal foram elaborados Fonte: Elaborado com base nos dados da pesquisa}


4.2 Documentos

Os documentos apresentados no Portal de Inclusão Digital são descritos no Quadro 4.

\begin{tabular}{|c|c|}
\hline Documentos & Descrição \\
\hline $\begin{array}{l}\text { Carta de Belém do Pará - VII Oficina para Inclusão } \\
\text { Digital (disponível criptografada no Portal) } \\
\text { Responsabilidade dos Ministérios do Planejamento e } \\
\text { das Comunicações }\end{array}$ & $\begin{array}{l}\text { Documento escrito em consenso pelas entidades da sociedade civil envolvidas } \\
\text { com os temas centrais das tecnologias de informação e comunicação para o } \\
\text { desenvolvimento humano, econômico e social. Apresentou-se a formulação de } \\
\text { uma política pública, integradora desse campo, ocorrida em } 2008 \text {, em Belém do } \\
\text { Pará. }\end{array}$ \\
\hline $\begin{array}{l}\text { Cartilha de Montagem de Telecentros } \\
\text { Responsabilidade da Secretaria de Inclusão Digital e } \\
\text { do Ministério das Comunicações }\end{array}$ & Documento com todas as informações sobre a montagem de telecentros no Brasil. \\
\hline
\end{tabular}

Quadro 4. Documentos do Programa Nacional de Inclusão Digital Fonte: Portal Inclusão Digital (2013)

A Carta de Belém do Pará (dados ausentes no Portal e encontrados no endereço eletrônico: www.maristas.org.br/portal/pagina. asp?IDPag=651) é o documento indicador de que desde 2001 a sociedade civil vem criando e alcançando metas em relação à Inclusão Digital, tais como: iniciativas de recondicionamento de equipamentos e metarreciclagem; uso e migração para SOFTWARE Livre nas iniciativas públicas e governamentais de inclusão digital; política de desenvolvimento de Softwares Públicos e criação de um Grupo de Trabalho para definir a integração das iniciativas de inclusão digital no país.

Segundo as representações que escrevem a Carta (Cidadania Digital; Coletivo Digital; Intervozes; Associação Software Livre; Rede Marista de Solidariedade (RS); Rits; Sampa.org; Projeto Saúde \& Alegria), há um discurso comum para orientar suas ações.
Diante disso:

a) repudiam o Projeto de Lei 84/99 (ex-PLC 89/03), que trata "dos crimes contra a segurança dos sistema informatizados" por tratar o compartilhamento de conhecimento como crime, sem a existência de uma legislação específica de direitos na internet, abrindo espaço para a violação de direitos civis básicos.

b) insistem que o Brasil precisa de uma política pública integrada que coloque a cidadania no horizonte da sociedade da informação.

c) reivindicam um conjunto de 25 ações gerais para uma política pública de tecnologias de informação e comunicação a serviço da inclusão digital.

Das 25 reivindicações apresentadas pela Carta, podem ser destacadas:

a) ampliação e disseminação do de- 
bate com toda sociedade civil visando construir consenso para avançar na implementação de marcos regulatórios e de políticas públicas que assegurem a sustentabilidade e permanência de iniciativas de inclusão digital.

b) diversos programas sociais e políticas públicas, voltados para assistência social, em que criança e adolescente, inserção produtiva, educação de jovens e adultos tenham como um de seus componentes as ações de inclusão digital.

c) iniciativas de inclusão digital que assegurem uma gestão participativa das comunidades onde estão localizadas e que representem um critério preponderante nos editais públicos.

d) criação em lei do Conselho Nacional de Inclusão Digital, com ampla participação de entidades da sociedade civil e movimentos sociais.
A Cartilha de Montagem de Telecentros é um documento técnico do Programa Nacional de Apoio à Inclusão Digital nas Comunidades - Telecentros.BR. Nela constam as informações referentes ao Programa, as condições físicas e materiais para constituição e funcionamento de um telecentro, as diretrizes de funcionamento de um telecentro, as atividades que podem ser desenvolvidas nos telecentros, os compromissos e contrapartidas dos que pactuam com Governo Federal, entre outras informações de engenharia.

Esses dois documentos foram os únicos apresentados pelo Portal, mesmo diante da existência concreta do Programa de Inclusão Digital por mais de oito anos - existe desde 2005.

Diante do que se apresenta, elaborou-se o Quadro 5, que informa para quê e para quem os Documentos de âmbito federal foram formulados.

\begin{tabular}{|c|c|c|}
\hline Documento & $\begin{array}{l}\text { Para quê } \\
\text { (objetivo) }\end{array}$ & $\begin{array}{l}\text { Para quem } \\
\text { (público-alvo) }\end{array}$ \\
\hline Carta de Belém do Pará & $\begin{array}{l}\text { Elaborar uma pauta para a formulação } \\
\text { de uma política pública, integradora de } \\
\text { Inclusão Digital. }\end{array}$ & $\begin{array}{l}\text { 1. Gestores públicos nas diferentes esferas governamentais } \\
\text { 2. Demais entidades da sociedade civil }\end{array}$ \\
\hline $\begin{array}{l}\text { Cartilha de Montagem de } \\
\text { Telecentros }\end{array}$ & $\begin{array}{l}\text { Orientar a montagem de telecentros pelo } \\
\text { Brasil. }\end{array}$ & $\begin{array}{l}\text { 1. Orgãos do Governo Federal } \\
\text { 2. Estados } \\
\text { 3. Distrito Federal } \\
\text { 4. Municípios } \\
\text { 5. Sociedade civil }\end{array}$ \\
\hline
\end{tabular}

Quadro 5. Para quê e para quem dos Documentos de âmbito federal foram elaborados Fonte: Elaborado com base nos dados da pesquisa 
Ainda fica a dúvida: Por que não foram depositados mais documentos relativos ao Programa - não incluindo a legislação pertinente -, apesar de estar vigente por tantos anos?

Algumas das Ações, Programas e Documentos não estavam disponíveis no Portal do Programa e foram pesquisadas em sites paralelos. Percebeu-se claramente, pelas indicações em latim das páginas, que o Portal do Programa ainda estava em construção, no entanto estava à disposição para consulta de qualquer pessoa que 0 acessasse, sem apresentar os dados pertinentes ao que informava o link inicial.

Logo ao fim da realização desta pesquisa, observou-se que o Portal e todos os links relacionados entraram em manutenção, fato que pode ter sido ocasionado/impulsionado pela repercussão dos movimentos de rua provindos das redes sociais e suas demandas de inclusão e de maior comunicação com o poder público.

\section{Considerações finais}

Este estudo baseou-se em uma pesquisa realizada no Portal de Inclusão Digital do Governo Federal Brasileiro em relação a Ações, Projetos, Programas e Documentos de âmbito federal, apontando seus objetivos e públicos-alvo. Dessa forma, buscou ressaltar as ações, ou ausência delas, conforme apresentado pelo governo federal, especificamente no âmbito do poder executivo. Portanto os resultados não apresentam a totalidade das ações, programas e projetos desenvolvidos no país, já que este estudo não assume como objeto de pesquisa as ações desenvolvidas por outros entes governamentais, como no caso dos Estados e municípios, nem mesmo de ações realizadas por outros poderes, como no caso do legislativo federal, ou dessa instância nos Estados e municípios.

A metodologia foi desenvolvida e aplicada a partir da navegação orientada, a qual foi a principal fonte de dados, definindo o modo de correr links e páginas, bem como os critérios e parâmetros para qualificar os objetos catalogados ao longo da navegação, de acordo com as categorias encontradas.

Os resultados indicam que o Portal governamental sobre o tema Inclusão Digital está desatualizado quanto às informações sobre suas Ações, Projetos, Programas e Documentos, pois muitas de suas páginas estão vazias e alguns dos programas e projetos apresentados foram descontinuados. Para que essa pesquisa fosse concluída com êxito, foi necessário realizar a procura de outros sites para obtenção de mais informações, as quais foram incluídas neste estudo.

Quanto ao resultado referente à discussão sobre Ações, Projetos e Programas, verificou-se que os objetivos são: levar computadores e conectividade às pessoas de baixa renda; capacitar pessoas na prática das técnicas computacionais; difundir o acesso ao conhecimento científico; permitir que pessoas de baixa renda possam comprar computadores de qualidade; fomentar o uso do Linux, outros softwares livres e padrões abertos nos órgãos públicos, e capacitar cidades tecnologicamente para o acesso à internet. Os públicos-alvo encontrados são os organismos públicos federais, os municípios e a população de baixa renda. Nota-se que, nesse item, houve uma dicotomia nos objetivos: ora foi a 
população de baixa renda a beneficiária do programa, ora foram os entes públicos.

Quanto ao resultado referente aos Documentos, foram identificados os seguintes objetivos: elaborar uma pauta para a formulação de uma política pública integradora de Inclusão Digital e orientar a montagem de telecentros pelo Brasil. Os públicos-alvo encontrados são os organismos públicos e a sociedade civil em ambos os casos. Observa-se que, apesar de os públicos serem os mesmos para os documentos, eles versam sobre assuntos diferentes. Enquanto um é exclusivamente técnico e objetivo, o outro, a Carta de Belém, contém uma gama de proposições subjetivas.

Diante disso, ressalta-se que as Ações, Projetos, Programas e Documentos dão ênfase à Inclusão Digital, Informacional e Social, seja para organismos públicos, seja para a sociedade de baixa renda. No entanto, percebeu-se que o Portal não está preparado para a divulgação e acolhimento desses públicos, já que as informações pertinentes às Ações, Projetos, Programas e Documentos não estavam delineadas ou sequer existiam. Além disso, apresentavam programas que já não estão mais em vigência. A gama de organismos envolvidos também é um fator que interfere para que essa Inclusão promovida pelo Governo Federal seja alcançada de fato.

Percebe-se que falta maturidade tecnológica no Governo Executivo para promover e divulgar a Inclusão Digital e permitir acesso àqueles que têm interesse em praticá-la. O Portal que está em manutenção desde sua criação só voltou a ser manipulado novamente a partir dos movimentos de rua ocorridos em julho de 2013, como se pode observar ao final da discussão apresentada. Por conta dessa imaturidade tecnológica, deixou-se passar reivindicações da sociedade civil, como as indicadas na Carta de Belém, que poderiam ter acelerado consideravelmente os avanços nas discussões sobre o tema pelo país. Ou seja, a Inclusão Digital no Brasil ainda é tratada quase que exclusivamente como inserção de computadores. Contudo, suas técnicas e seus programas com ênfase social têm pouca aderência, fazendo alusão aos dados da pesquisa TIC domicílios de 2009.

No entanto, Inclusão Digital, como se observou pela discussão apresentada na fundamentação teórica, significa mais do que distribuição ou conhecimento sobre a utilização de aplicativos, máquinas e equipamentos e gestões direcionadas a isso. Ela precisa conectar as pessoas à rede, não apenas de forma mecânica a partir de hardwares e softwares, mas de forma ampliada e mais completa, na qual o usuário saiba o que acessar, qual informação procurar, como relacionar um assunto com outro e como utilizar em benefício próprio.

As limitações deste estudo se devem a alguns fatores técnicos, tais como "links quebrados", páginas vazias do Portal Inclusão Digital e poucas informações atualizadas sobre os programas. Também pode ser citada como limitação a existência de apenas dois documentos no Portal que tratam do tema, além dos poucos índices que retratam a situação da Inclusão Digital no Brasil. Outro fator é que a análise se deteve apenas aos programas do quadro do Governo Federal.

Pesquisas futuras devem analisar novamen- 
te o Portal do Programa a fim de verificar se a manutenção manifestada a partir de agosto de 2013 apresenta diferenças nos conteúdos e comunicabilidade com o cidadão e instituições interessadas na Inclusão Digital. Sugere-se, também, que sejam feitas pesquisas paralelas nos sites dos Programas e Ações indicados pelo Portal Inclusão Digital, com o intuito de conhecer cada ação do governo brasileiro sobre o tema, bem como outros programas e ações indicados neste artigo, seja da esfera estadual, seja da municipal, bem como por parte da sociedade.

\section{Referências}

Alonso, L. B. N., Ferneda, E., \& Santana, G. P. (2010). Inclusão digital e inclusão social: contribuições teóricas e metodológicas. Revista Barbarói. Santa Cruz do Sul, n. 32, jan./jul. Recuperado em 30 julho, 2013, de http://online.unisc.br/seer/index.php/barbaroi/article/view/1289/1092

Bernardi, C. A., \& Dias, J. C. (2008) Uma reflexão sobre a contribuição das organizações públicas e privadas à inclusão digital. Revista Capital Científico do Setor de Ciências Sociais Aplicadas [online], vol. 6, n. 1 jan./dez.

Bogdewic, S. P. (2011). Participant observation. In: Crabtree, B. e Miller, W. L. (Orgs.) Doing qualitative research (2a ed.). Thousand Oaks: Sage Publications, 1999. 406 p.

Bonilla, M. H. S., \& Pretto, N. D. L. (Org.) Inclusão digital: polêmica contemporânea. Salvador: EDUFBA, v. 2. 188 p.

Bonilla, M. H. S., \& Oliveira, P. C. S. (2011).
Inclusão digital: ambiguidades em curso. In: Bonilla, M. H. S., \& Pretto, Nelson De Luca. Inclusão digital: polêmica contemporânea. Salvador: EDUFBA, v. 2. pp. 23-48.

Brasil. Ministério das Comunicações (2013a). Programa Nacional de Banda Larga (PNBL). Recuperado em 31 agosto, 2015, de www. mc.gov.br/acoes-e-programas/programa-nacional-de-banda-larga-pnbl

Brasil. Ministério do Planejamento, Orçamento e Gestão (2013b). Gov.Br (site). Recuperado em 1 julho, 2015, de www.governoeletronico.gov.br

Carvalho, J. O. F. (2003). O papel da interação humano-computador na inclusão digital. Revista Transinformação, Campinas (SP), v. 15 , n. 3, pp. 75-89. Recuperado em 29 juIho, 2013, de www.brapci.ufpr.br/documento. php?dd0 $=0000000449 \&$ dd $1=668 \mathrm{dd}$

Carvalho Neto, E. S., Cruz, F. N., \& Hetkowski, T. M. (2008). Sociedade da informação: tic e programas de inclusão digital. In: Hetkowski, T. M. (Org.) Políticas públicas \& inclusão digital. Salvador: EDUFBA. 338 p. Recuperado em 28 julho, 2013, de http://api. ning.com/files/cz-1JWPeSBWHVPZAzDezp3-7jfwwzZly3aJIQt6TYTuap55O2QGTBY 10dMxDXrxrAM6ksloTpPcrAtSEK4qUF*2JX fbuq $^{*} Z^{*} /$ Politicaspublicaseinclusaodigital.pdf

Duarte, T.C., \& Fumes, R. C.P. (2012). Políticas Públicas de Inclusão Digital no Brasil: Problemase Perspectivas.Anais...In:CELACOM, 16, Bauru. CELACOM, 2012. Recuperado em 28 julho, 2013, de www2.faac.unesp.br/celacom/ anais/Trabalhos\%20Completos/GT1-\%20 Pensar\%20e\%20Comunicar\%20a\%20 Am\%C3\%A9rica\%20Latina/117.Tatiana\%20 
e\%20Rodrigo_Pol\%C3\%ADticas\%20 P \% C $3 \%$ B A b I ic a s $\% 20$ de $\% 20$ Inclus\%C3\%A3०\%20Digital.pdf

Lévy, P. (1999). Cibercultura. São Paulo: Editora 34. 264 p. Recuperado em 28 julho, 2013, de http://pt.scribd.com/doc/11036046/ Cibercultura-Pierre-Levy

Marconi, M. A., \& Lakatos, E. M. (2007). Metodologia científica. 5a ed. São Paulo: Atlas. $312 \mathrm{p}$.

Martins, T. S., \& Lucas, E. R. O. (2009). Os programas de inclusão digital do Governo Federal sob a óptica da competência informacional. Liinc em Revista, v. 5, n. 1, março, Rio de Janeiro, pp. 82-99. Recuperado em 30 julho, 2013, de http://revista.ibict.br/liinc/ index.php/liinc/article/viewFile/293/196

Mattos, F. A. M. (2005). Os Limites da Inclusão Digital no Brasil. Anais... In: ENLEPICC, 5. Salvador, ENLEPICC. Recuperado em 15 julho, 2013, de www.rpbahia.com.br/bibliote$\mathrm{ca} /$ pdf/FernandoMattos.pdf

May, T. (2004). Pesquisa social: questões, métodos e processos. Trad. Carlos Alberto Silveira Netto Soares. 3a ed. Porto Alegre: Artmed. $288 \mathrm{p}$.

Neves, B. C., \& Gomes, H. F. (2008). A inclusão digital e o contexto brasileiro: uma experiência nos domínios de uma universidade. BID. Textos Universitarios de Biblioteconomia i Documentació, v. 21, pp. 1-15. Recuperado em 30 julho, 2013, de http://bid. ub.edu/21/coelh2.htm

Richardson, R. J. et al. (2011). Pesquisa social: métodos e técnicas. $3 a$ ed. revista e ampliada. São Paulo: Atlas. 334 p.

Silva Neto, C., \& Carvalho, J. O. F. (2008). O programa de inclusão digital do governo brasileiro: análise sob a perspectiva da interseção entre ciência da informação e interação humano computador. Revista Digital de Biblioteconomia e Ciência da Informação. Campinas, v. 5, n. 2, pp. 25-52, jan./jun. Recuperado em 30 julho, 2013, de www.sbu. unicamp.br/seer/ojs/index.php/rbci/article/ view/378

Silva, S. P. (2009). Estado, democracia e internet: requisitos democráticos e dimensões analíticas para a interface digital do Estado. 277 f. Tese de doutorado em Comunicação e Culturas Contemporâneas. Universidade Federal da Bahia, Salvador.

Santos, A. J. P., \& Hetkowski, T. M. (2008). Software livre: políticas públicas de inclusão digital. In: Hetkowski, T. M. Políticas públicas \& inclusão digital. Salvador: EDUFBA. 338 p. Recuperado em 28 julho, 2013, de http://api. ning.com/files/cz-1JWPeSBWHVPZAzDezp3-7jfwwzZly3aJIQt6TYTuap55O2QGTBY 10dMxDXrxrAM6ksloTpPcrAtSEK4qUF*2JX fbuq $^{*} Z^{*} /$ Politicaspublicaseinclusaodigital.pdf

Tramontin, A., \& Borges, D. F. (2007) Um caminho para a inclusão digital: o programa GESAC. Revista Organ. Soc. [online], vol. 14, n. 42, pp. 167-184. ISSN 1984-9230. 